\title{
Correction to: Application of cerium phosphate in preparing anti-ultraviolet PET fibers with masterbatch method
}

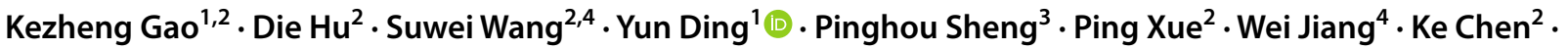 \\ Hui Qiao'
}

Published online: 5 February 2021

(C) The Polymer Society, Taipei 2021

\section{Correction to: Journal of Polymer Research (2020) 27: 361 \\ https://doi.org/10.1007/s10965-020-02324-w}

The original version of this article unfortunately contained a mistake. The short note saying the equal contributions of the authors "Kezheng Gao, Die Hu and Suwei Wang" was missed out. It should exactly say like this:

"Kezheng Gao, Die Hu and Suwei Wang contributed equally to this work"

Publisher's Note Springer Nature remains neutral with regard to jurisdictional claims in published maps and institutional affiliations.

The original article can be found online at https://doi.org/10.1007/ s10965-020-02324-w.

Yun Ding

dingyun@mail.buct.edu.cn

1 College of Materials Science and Engineering, Beijing University of Chemical Technology, Beijing 100029, China

2 College of Mechanical and Electrical Engineering, Beijing University of Chemical Technology, Beijing 100029, China

3 State Key Laboratory of Bio-Based Fiber Manufacturing Technology, China Textile Academy, Beijing 100025, China

4 National Special Superfine Powder Engineering Research Center, Nanjing University of Science and Technology, Nanjing 210094, China 